Compostos Organofosforados e seu Papel na Agricultura

\author{
Barboza, H. T. G.; Nascimento, X. P. R.; Freitas-Silva, O.; Soares, A. G.; \\ DaCosta, J. B. N.*
}

Rev. Virtual Quim., 2018, 10 (1), 172-193. Data de publicação na Web: 2 de março de 2018

http://rvq.sbq.org.br

\title{
Organophosphorus Compounds and their Role in Agriculture
}

\begin{abstract}
The agricultural need for greater food production in smaller and smaller spaces led to the search for technologies capable of supplying higher yield per area, which separates the use of agricultural pesticides. In addition, attack by microorganisms such as fungi, bacteria and viruses is one of the safest causes of post-harvest losses of fruits and vegetables. Among the products used as pesticides, organophosphorus compounds (OPs) are even more important for agricultural activities around the world, constituting a very diverse family of organic chemicals. OPs have been banned from agriculture in several countries because of their high toxicity, once they can be inhibitors of the enzyme acetylcholinesterase (AChE), which plays a critical role in the proper functioning of nerve cells. However, a toxicity is related to molecule structure. Thus, a new generation of OPs have studied, non-inhibitors of AChE and with greater biological activity.
\end{abstract}

Keywords: Organophosphorus compounds; Organophosphates; Agriculture; Pesticides; postharvest; Acetylcholinesterase.

\section{Resumo}

A necessidade agropecuária de maior produção de alimentos em espaços cada vez menores levou à busca de tecnologias capazes de proporcionar maior rendimento por área, o que disseminou o uso de defensivos agrícolas. Além disso, o ataque por microrganismos como fungos, bactérias e vírus, é provavelmente uma das causas mais sérias de perdas pós-colheitas de frutas e hortaliças. Dentre os produtos utilizados como defensivos, os compostos organofosforados (OFs) foram e ainda são importantes para as atividades agrícolas em todo o mundo, constituindo uma família muito diversificada de produtos químicos orgânicos. Os OFs foram banidos da agricultura em vários países devido sua alta toxicidade, pois podem ser inibidores da enzima acetilcolinesterase (AChE), que desempenha um papel crítico no bom funcionamento das células nervosas. No entanto, a toxicidade está relacionada a estrutura da molécula. Desta forma, têm-se estudado uma nova geração de OFs, não inibidores da AChE e com maior atividade biológica.

Palavras-chave: Compostos Organofosforados; Agricultura; Pesticidas; Pós-colheita; Acetilcolinesterase.

\footnotetext{
* Universidade Federal Rural do Rio de Janeiro, BR-465, Km 7, Seropédica, CEP 23.890-000, Rio de Janeiro-RJ - Brazil.

Mdacosta@ufrri.br

DOI: $10.21577 / 1984-6835.20180015$
} 


\section{Compostos Organofosforados e seu Papel na Agricultura}

\section{Henriqueta Talita G. Barboza, ${ }^{a}$ Xênia P. R. do Nascimento, ${ }^{b}$ Otniel F. Silva, ${ }^{a}$ Antonio G. Soares, ${ }^{\text {a João B. N. DaCosta }}{ }^{c}$}

a Embrapa Agroindústria de Alimentos, Pós-Colheita de Frutas e Hortaliças. Av. das Américas, 29501, Guaratiba, CEP 23020-470, Rio de Janeiro-RJ, Brasil.

b Instituto Federal de Química do Rio de Janeiro, Rua Lúcio Tavares, 1045, Centro, CEP 26530060, Nilópolis-RJ, Brasil.

' Universidade Federal Rural do Rio de Janeiro, BR-465, Km 7, Seropédica, CEP 23890-000, Rio de Janeiro-RJ, Brasil.

* dacosta@ufrrj.br

1. Introdução

2. Defensivos Agrícolas (DA)

3. A química dos OFs

4. OFs na agricultura

5. Fungicidas OFs e doenças pós-colheita

6. OFs e inibição da enzima AChE

7. Potenciais dos OFs

\section{Introdução}

A demanda por produtos agrícolas enfrenta um aumento sem precedentes, uma vez que a previsão de população mundial deverá ser de nove bilhões até 2050. A maioria dessa população residirá em países em desenvolvimento. Em 2050, haverá um aumento de $35 \%$ na demanda de alimentos, principalmente da China, Índia e outros países asiáticos, além do continente africano. No entanto, o crescimento mundial da produtividade agrícola tem diminuído e o crescimento anual estimado é de apenas $1 \%$ nas próximas duas décadas, muito mais lento do que as tendências históricas. ${ }^{1} \mathrm{~A}$ necessidade agropecuária de maior produção de alimentos, em espaços cada vez menores no passado, levou à busca de tecnologias capazes de proporcionar maior rendimento por área, havendo assim a proliferação do uso de defensivos agrícolas (DA). ${ }^{2}$

O Brasil dispõe de um enorme potencial agrícola. O agronegócio é responsável por parcela importante do Produto Interno Bruto (PIB) e o país é um dos maiores produtores e fornecedores globais de grãos, cana-deaçúcar, carne e produtos florestais, tendo uma das estruturas de custos mais 
competitivas do mundo. Os citros são as frutas mais produzidas e consumidas no mundo e o Brasil se destaca como o maior produtor de laranja e maior exportador do seu suco. ${ }^{3,4}$ No entanto, a deterioração póscolheita resultante da infecção de patógenos fúngicos é um grande problema em várias culturas, no mundo inteiro, afetando não só a qualidade de produtos hortifrutícolas, como também o seu valor de comercialização, gerando perdas econômicas substanciais. Estima-se que nos países desenvolvidos, cerca de $20-25 \%$ das frutas e produtos hortícolas colhidos sejam afetados por fitopatógenos durante o manejo póscolheita.

O modelo agrário hegemônico no Brasil está baseado em monocultivos para exportação que são intensivos em tecnologias mecanizadas e no uso de DA. O país tornou-se o principal consumidor mundial desses produtos e estima-se que este será o mercado que mais crescerá num futuro próximo. ${ }^{5}$ Os pesticidas são produtos criados e desenvolvidos para serem utilizados no ambiente como uma ferramenta para o agricultor minimizar o prejuízo causado pela ação danosa de insetos, fungos, plantas invasoras, entre outros.

Os pesticidas são essenciais para a produção mundial agrícola, especialmente quando se fala em culturas como milho, trigo e soja. A atividade inseticida do OF é decorrente, na grande maioria dos casos, de sua ação neurotóxica que ocorre através da inibição irreversível da enzima acetilcolinesterase (AChE), uma enzima responsável pela degradação da acetilcolina, neurotransmissor principal no sistema nervoso central dos insetos. A inibição da sua atividade por inseticidas OFs, podem induzir mudanças no sítio ativo da enzima, levando ao acúmulo de acetilcolina dentro da sinapses e interromper a transmissão do sinal, podendo causar a morte. ${ }^{6}$ No entanto, a dinâmica da interação da AChE com os OFs depende da sua afinidade pela enzima, o qual é comumente representado como constante de afinidade Ks. ${ }^{7}$

Em contrapartida, compostos inibidores da AChE têm sido amplamente reconhecidos como um tratamento eficaz para a doença de Alzheimer, pois atuam impedindo o colapso da acetilcolina (ACh), através da inibição da AChE nas regiões do cérebro (córtex e hipocampo) relevantes para doença de Alzheimer, atrasando assim o desenvolvimento de deficiências cognitiva e neurodegeneração e aliviando o sintomas.

\section{Defensivos Agrícolas (DA)}

Defensivos agrícolas, defensivos químicos, agrotóxicos, pesticidas, praguicidas são algumas das inúmeras denominações relacionadas a um grupo de substâncias químicas utilizadas no controle de pragas em animais, vegetais e doenças de plantas. No entanto, o conceito de DA difunde a ideia de que seu uso aumenta a produtividade das lavouras. Na verdade, eles constituem uma categoria especial de insumos, diferente dos fertilizantes, corretivos e sementes melhoradas. A diferença está no fato de que se forem utilizados dentro das técnicas recomendadas, têm sempre como resposta, uma produtividade agrícola maior, sem trazer prejuízos a saúde do trabalhador rural, bem como aos consumidores dessas culturas. 0 papel dos DAs é evitar a quebra de safras por ataque de pragas ou doenças nas culturas ou de servir como coadjuvante na preservação das safras armazenadas. Dessa forma, atua como um agente repressivo de elementos exógenos às plantas ou ao produto colhido. ${ }^{8}$

O uso de produtos químicos no controle de pragas da agricultura, para que não haja diminuição da produtividade agrícola, é uma prática comum há muito tempo. No início, utilizava-se apenas um pequeno número de compostos inorgânicos, principalmente aqueles baseados em formulações envolvendo elementos químicos, como cobre e arsênio. ${ }^{8,9}$ Até o início do século XIX, era relativamente fácil elevar a produção de alimentos, através da incorporação de terras abundantes em todo o mundo. A partir do século $X X$, esse cenário mudou e para 
atender à crescente demanda global de alimentos, houve a necessidade do aumento da produtividade através da mecanização, da irrigação, do emprego de capitais humanos mais avançados, do melhoramento das plantas e do combate às pragas, com uso de DA. ${ }^{10}$

A indústria de DA desenvolveu-se com base na indústria química, aliando conhecimentos de química orgânica às ciências agronômicas. Ela está incluída no segmento de química fina, caracterizado por fabricar produtos de elevado valor unitário, quando comparados aos produtos de outros segmentos, como a química básica. 0 crescimento do setor apoiou-se na expansão da utilização de herbicidas e fungicidas. ${ }^{11}$

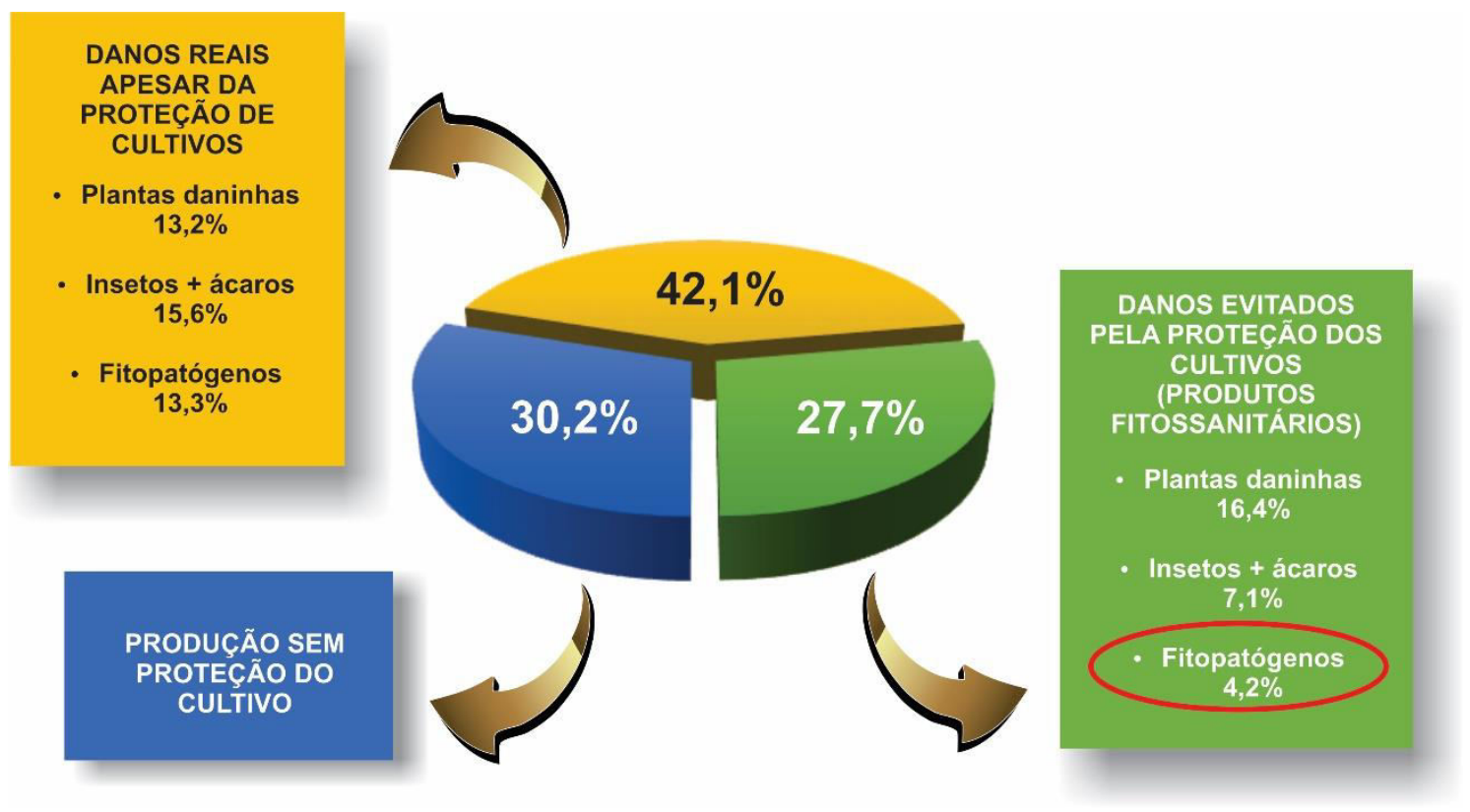

Figura 1. Danos na Produção agrícola mundial por pragas. (Adaptado de: J.O. Menten\&T.C. Banzato, 2016).

Embora a agricultura seja praticada pelo homem há mais de dez mil anos, o uso intensivo de DA para o controle de pragas e doenças das lavouras tem cerca de 80 anos. ${ }^{12}$ Os DAs começaram a se popularizar em plena Segunda Guerra Mundial, quando os sistemas agrários tiveram um profundo impacto em relação ao controle de pragas na agricultura com a descoberta e uso do diclorodifeniltricloroetano (DDT). Esse produto, de baixo custo e eficiência como inseticida, levou ao seu descobridor Paul Mueller a ganhar o prêmio Nobel de Medicina de 1948. A descoberta das propriedades inseticidas do DDT (1940) e dohexaclorociclohexano (HCH) (1940-1942) deu grande impulso no combate aos insetos, de modo que, a partir da década de 1940, os inseticidas organoclorados (OC) foram amplamente utilizados na agricultura, na indústria pecuária, nos programas de combate a insetos transmissores de doenças e nas campanhas de saúde pública. ${ }^{13}$

Mais tarde quando a comunidade científica passou a conhecer melhor os mecanismos de atuação dos $O C$ no meio ambiente e dos seus efeitos à saúde humana, a utilização desses compostos começou a ser substituída por outros tipos de inseticidas. A sua alta lipofilicidade e resistência à degradação, levando à bioacumulação na cadeia alimentar e depois em tecidos e 
fluidos humanos, fez com que na década de 70 , houvesse a proibição desses compostos. Contudo até a década de 1990 a comercialização ainda era permitida em alguns países. No entanto, o grande sucesso desse produto no combate às pragas fez com que surgissem uma nova geração de OF sintéticos com propriedades menos tóxicas, fortalecendo a grande indústria de DAs presentes nos dias de hoje. ${ }^{14-16}$

De um modo geral, o maior consumo desses agentes no meio rural é, nesta ordem, de herbicidas, inseticidas e fungicidas. Os herbicidas são os mais utilizados, no entanto e geralmente, a toxicidade deste grupo de substâncias é inferior à dos inseticidas. De acordo com as suas propriedades químicas, os pesticidas podem ser agrupados em 7 classes distintas, incluindo organoclorados, organofosforados, carbamatos, piretróides, aminas, anilinas e compostos heterocíclicos azotos. Pesticidas organoclorados tradicionais, geralmente, têm estrutura química constante e muitas vezes se acumulam e persistem no ambiente. Os OF se os carbamatos apresentam como mecanismo de ação a inibição da enzima acetilcolinesterase. ${ }^{17-19}$ Os pesticidas OFs são usados como substitutos de pesticidas OC em muitos países hoje em dia, pois degradam-se mais facilmente no meio ambiente, ou seja, apresentam um tempo de meia vida bastante curto. Eles são os inseticidas mais utilizados para aumentar a produtividade agrícola. Aproximadamente, $34 \%$ das vendas mundiais principalmente para o controle de insetos na agricultura e nas residências, é devido à sua baixa persistência ambiental e alta eficácia. ${ }^{10,20}$

Esses compostos podem ser aplicados como inseticidas pré-colheita, mas também podem ser usados diretamente sobre o produto durante $o$ armazenamento, para protegê-lo de pragas. ${ }^{21-24}$

No Brasil, a agricultura é um setor primário, que gera renda para o país. As commodities agrícolas têm sido o foco principal da produção e da exportação brasileira. Globalmente, o Brasil é atualmente um dos principais produtores e exportadores de alimentos e especialista em cultivos em que $\mathrm{o}$ consumo de DA tem grande importância, como soja, cana-de-açúcar, milho, arroz, citros, café, algodão, hortaliças e outras frutas. No Brasil o consumo de DA teve um grande aumento a partir de 1960, chegando ao posto de principal consumido mundial desses insumos no ano 2008.Eles constituem um importante insumo para a agricultura, tendo atingido em 2010 um valor de vendas de US\$ 7,3 bilhões no Brasil, o correspondente a cerca de $7 \%$ do total das vendas de produtos agropecuário, que neste ano foi estimado em cerca de $\mathrm{R} \$ 180$ bilhões. Em 2011, o Brasil passou a ser destaque global relativo a este insumo, alcançando cerca de US\$ 8,5 bilhões/ano, se tornando assim o maior consumidor de DA na América Latina. ${ }^{10,25-27}$ Os gastos mundiais com agrotóxicos crescem continuamente e, de acordo com a Organização Mundial de Saúde (OMS), os países em desenvolvimento consomem cerca de $20 \%$ de todo o DAs produzido no mundo. Em decorrência da significativa importância, tanto em relação à escala de uso quanto à sua toxicidade, os DAs possuem uma ampla cobertura legal no país, com um grande número de legislação de seu uso, aplicação, resíduos máximos permitidos, entre outros. O referencial legal mais importante é a Lei № 7802/89, que rege o processo de registro de um produto agrotóxico, regulamentada pelo Decreto no $4074 / 02 .{ }^{27,28}$

\section{A química dos OFs}

Por definição, os OFs são compostos com pelo menos uma ligação $\mathrm{P}-\mathrm{C}$, uma ligação relativamente forte, nada fácil de ser clivada. Todos eles são produtos derivados do fósforo elementar, principalmente do alótropo $\mathrm{P}_{4}$, embora com algumas poucas exceções, não podem ser sintetizados diretamente do elemento fósforo, fazendo uso, em vez disso, de derivados deste elemento como tricloreto de fósforo $\left(\mathrm{PCl}_{3}\right)$, fosfito de trialquila $\left(\mathrm{P}(\mathrm{OR})_{3}\right)$, fosfina $\left(\mathrm{PH}_{3}\right)$ ou hipofosfito de sódio $\left(\mathrm{NaPO}_{2} \mathrm{H}_{2}\right)^{29}$ 
Os OFs são aqueles que, além do fósforo, contêm pelo menos um átomo de carbono. Eles constituem um grande grupo de produtos químicos utilizados nos últimos 60 anos para proteger a agricultura, a pecuária $\mathrm{e}$ saúde humana. A química dos heterociclos organofosforados sempre atraiu muita atenção por causa de suas potenciais propriedades biológicas únicas, como pesticidas sistêmicos, antifúngicos, antibacterianos, antileucêmicos, antiparasitários, antivirais, antiinflamatórios, antitumoral, anti-hipertensivos e antioxidantes. Na agricultura, eles têm uso generalizado em todo o mundo, principalmente como inseticidas, herbicidas e reguladores de crescimento de plantas. ${ }^{30}$

Os OFs são, principalmente, ésteres de ácido fosfórico e seus derivados. A estrutura química geral de um OF (Figura 2) compreende um átomo central de fósforo $(\mathrm{P})$ e a ligação característica envolvendo um grupo fosforila $(P=O)$, ou um grupo tiofosforila $(P=S)$ ou um grupo selenofosforila $(\mathrm{P}=\mathrm{Se}) .^{31}$

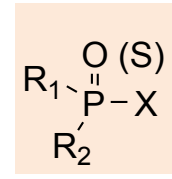

Figura 2. Estrutura geral dos OFs. X, representa halogênios, grupos alcóxidos, grupos alquil aminas, etc. e $R_{1}$ e $R_{2}$, geralmente são representações dos grupos alcoxila

O crescente interesse no estudo dos OFs ocorre devido à aplicação desses compostos como DA, drogas, polímero, perfume, removedor de tinta, revestimento protetor e na indústria automobilística. ${ }^{32,33}$

Com base nas características estruturais, Essas classes são divididas em pelo menos 12 tipos que incluem fosfina, fosfinito, fosfonito, fosfito, amino fosfinas, diamino fosfoninas, triamino fosfinas, sal de fosfônio, óxido de fosfina, fosfinato, fosfonatos e fosfato, podendo ter as correspondentes variações simplesmente pela troca do oxigênio $(P=O)$ pelo enxofre $(P=S)$ ou pelo selênio $(P=S e)$ para gerar os tio e seleno compostos, Figura $3 .^{31}$ 


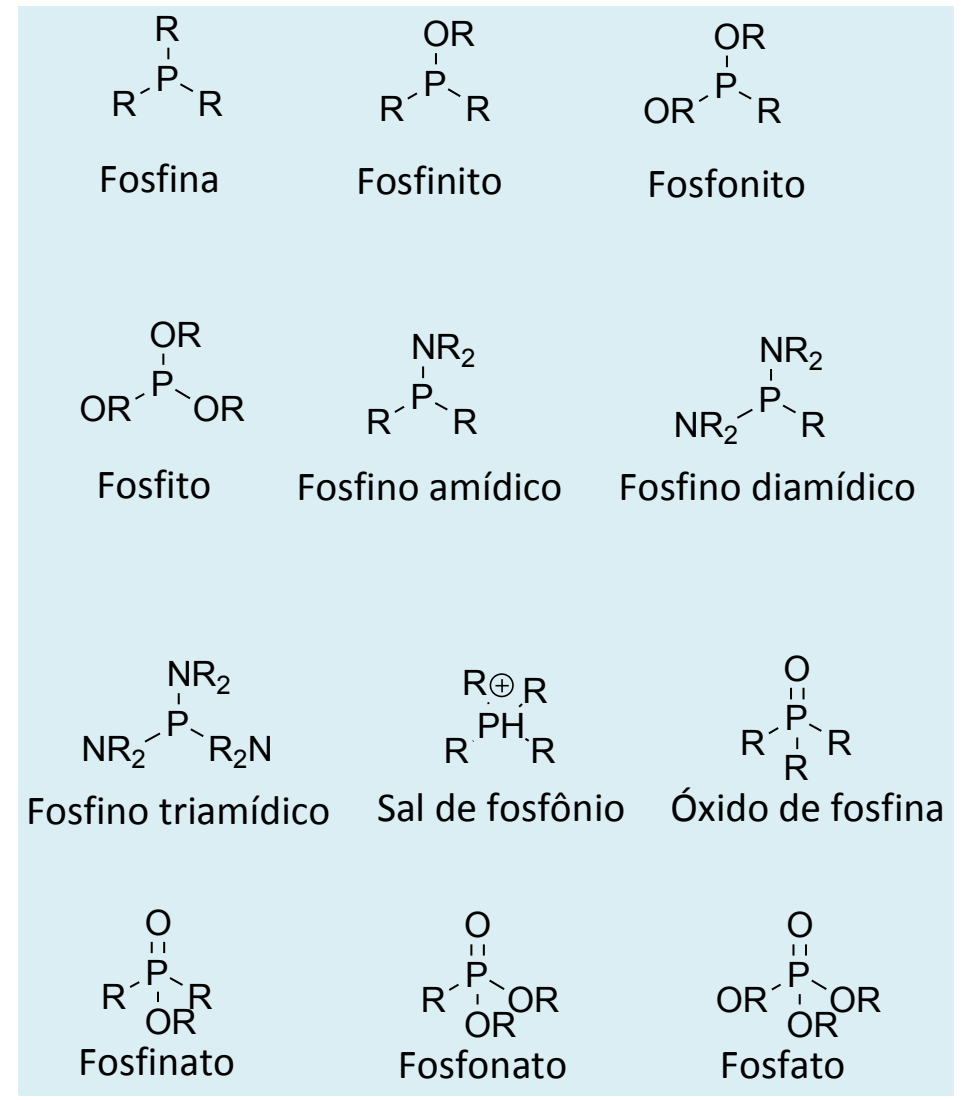

Figura 3. Exemplo das classes mais importantes dos compostos organofosforados

O estudo de fosfatos (ésteres de fósforo) e as suas reações são particularmente importantes pois servem como sistemas modelo para compreender muitas reações biológicas. ${ }^{32}$ Os compostos orgânicos de fósforo são intermediários valiosos na síntese orgânica. O método mais frequentemente utilizado envolve a reação de Atherton-Todd, um método de síntese clássica amplamente utilizado para a preparação de fosfatos e compostos de fósforo relacionados. Apesar da versatilidade deste método, ele tem limitações, tais como a falta de tolerância em relação a grupos funcionais e a geração de um grande número de regentes perigosos. ${ }^{34}$

Apesar de estudos extensivos, o mecanismo da reação de Atherton-Todd não é totalmente compreendido. Atherton e Todd descobriram essa reação em 1945 e propuseram um possível mecanismo que envolve um intermediário fosfato triclorometila. Mais tarde, Steinberg investigou o mecanismo da reação de Atherton-Todd, em 1950, e confirmou a formação de intermediários de $(\mathrm{RO}){ }_{2} \mathrm{P}(\mathrm{O}) \mathrm{Cl}$ na reação. Em 1985, Engel, também propôs um mecanismo plausível através de um intermediário de cloreto de fosforila pentacoordenado. No entanto, pouco se sabe sobre a estereoquímica da reação de Atherton-Todd. Em 1972, Mikolajczyk estudava a estereoquímica da reação de halogenetos de fósforo opticamente ativos com álcoois e aminas e descobriu que a reação prosseguia com inversão de configuração no centro de fósforo. Em 1980, Inch investigou a estereoquímica e o mecanismo de formação e quebra de ligação do fósforo em alguns ésteres de fósforo cíclicos de cinco/seis membros. Dentre os compostos de fósforo, o tricloreto de fósforo $\left(\mathrm{PCl}_{3}\right)$ se apresenta como 0 reagente fosforado mais utilizado na síntese de compostos organofosforados e demais compostos, por ser extremamente reativo, possuindo diversas aplicações sintéticas, as quais são mostradas no Esquema 1..$^{35,36}$ 


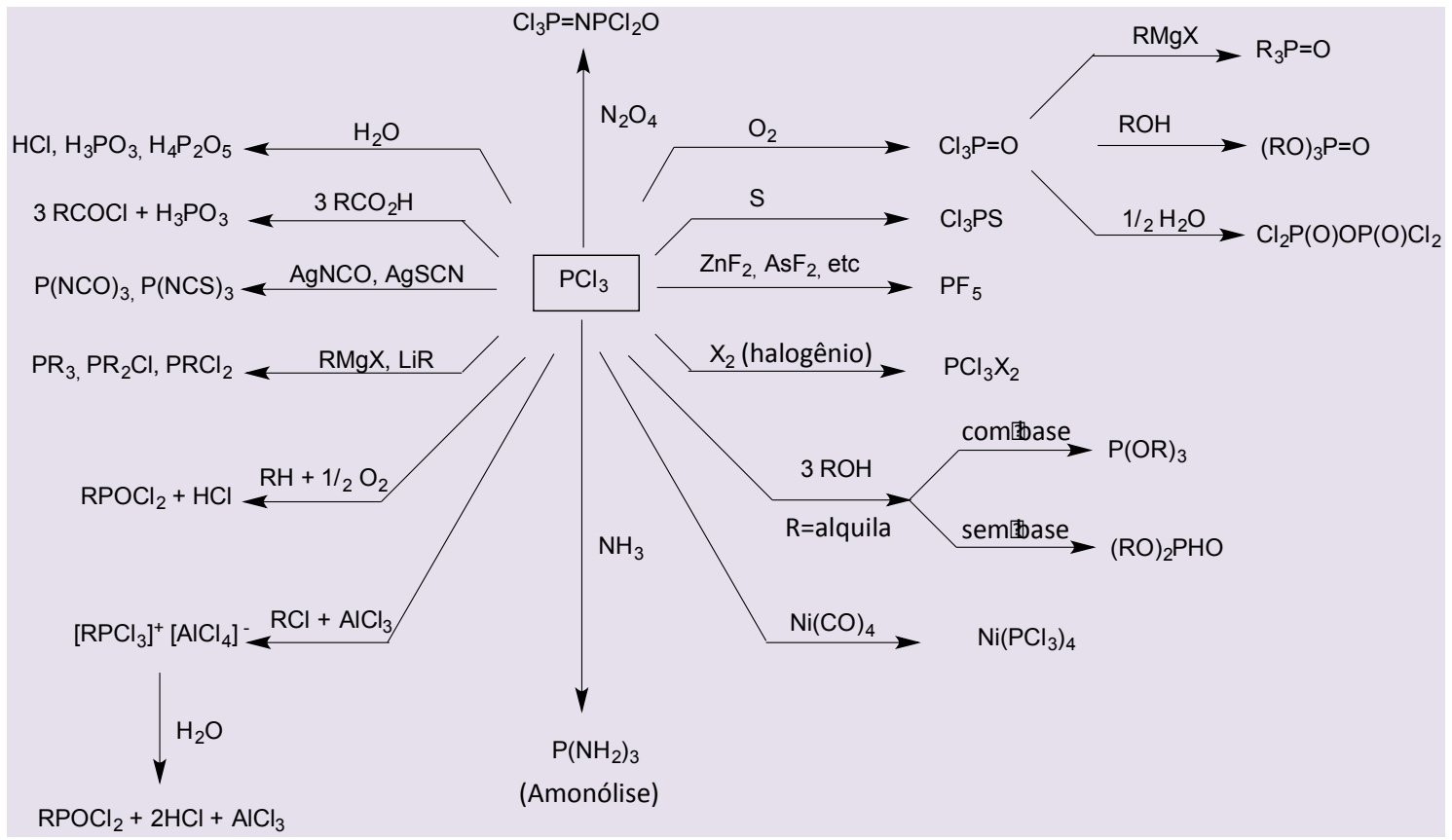

Esquema 1. Aplicações sintéticas do $\mathrm{PCl}_{3}$. Adaptado do Advanced Inorganic Chemistry, Cotton, F. A. e Wilkinson, G., $4^{\text {th }}$ Ed. pp.448

Uma reação clássica para a síntese de fosfatos e fosfitos ocorre entre o tricloreto de fósforo $\left(\mathrm{PCl}_{3}\right)$ e álcool, conforme é mostrado no Esquema 2.

Uma outra forma de obtenção de formação da ligação P-C é a reação de Michaelis - Arbuzov, que é uma maneira muito versátil de obtenção destes compostos a partir da reação entre fosfito de trialquila e halogeneto de alquila/arila, podendo ser realizada na presença de solvente, por aquecimento sob refluxo, como mostrado no Esquema $3{ }^{37}$

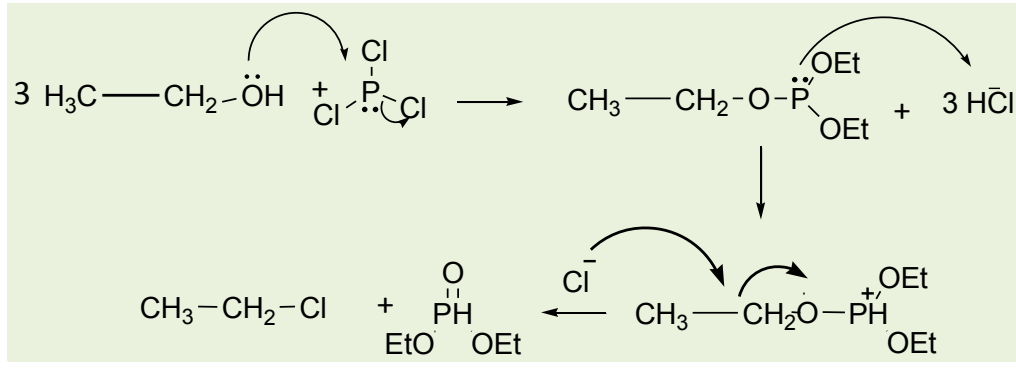

Esquema 2. Reações de álcool com $\mathrm{PCl}_{3}$

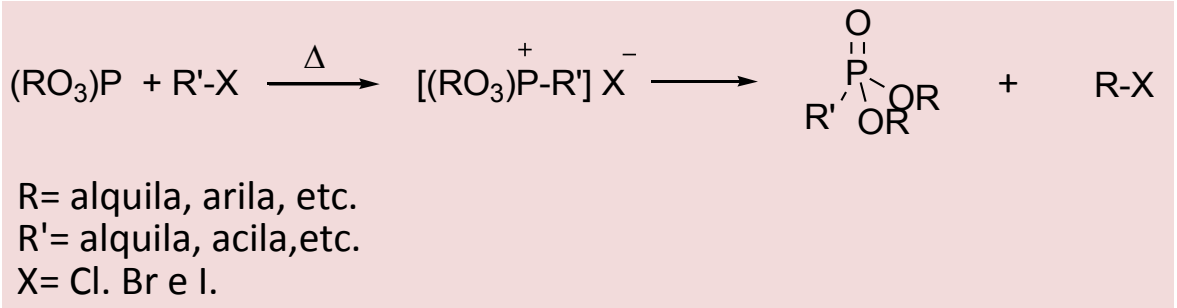

Esquema 3. Reação de Michaelis-Arbuzov 
A síntese de ésteres de fosfato é uma importante reação química na síntese orgânica, uma vez que eles encontraram uso na preparação de moléculas biologicamente ativas e também intermediário versátil na síntese de amidas e ésteres. Entre os ésteres de fosfato, os derivados de fosfonato são de interesse como fungicidas eficazes. Vários outros métodos estão disponíveis para a síntese de alquil/arilfosfonatos, mas nenhum deles possui a generalidade da reação de Michaelis-Arbuzov.

A formação de ligações do tricloreto de fósforo com aminas e iminas orgânicas gera vários compostos contendo uma ligação fósforo-nitrogênio. ${ }^{38} \mathrm{~A}$ ligação $\mathrm{P}-\mathrm{N}$, que caracteriza as fosforamidas, é geralmente formada por reações do tricloreto de fósforo $\left(\mathrm{PCl}_{3}\right)$, cloreto de fosforila $\left(\mathrm{POCl}_{3}\right)$ ou compostos trivalentes de fósforo com diferentes aminas ou amônia. Os métodos de síntese de fosforamidas foram descritos a partir de 1945 com uma série de trabalhos realizados por ATHERTON et al.(1945), usando, inicialmente, fosforilcloridratos de dialquila como agentes de fosforilação em meio anidro, conforme descrito no Esquema $4 .^{39}$

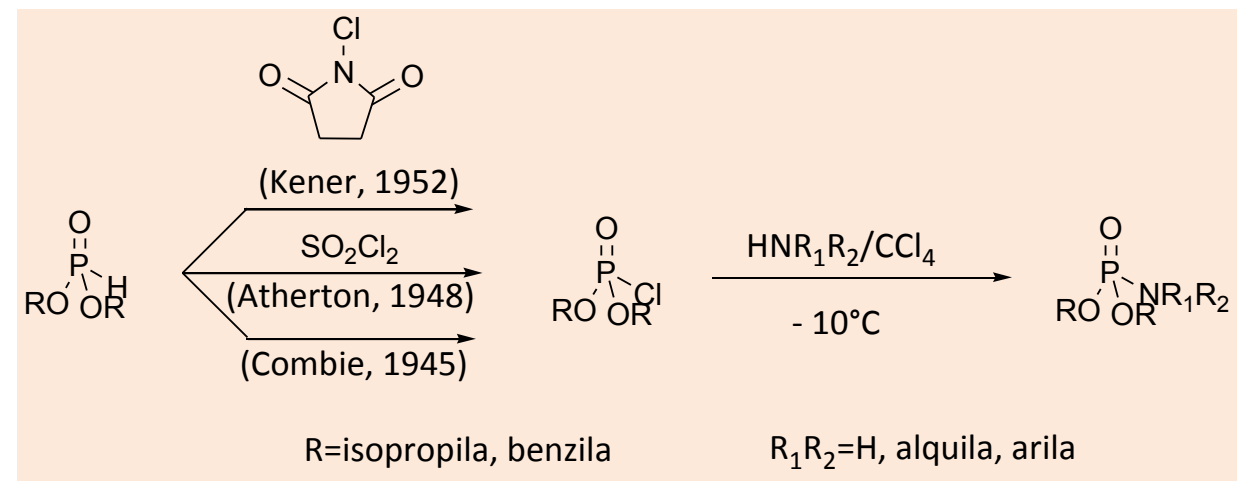

Esquema 4. Síntese de fosforoamidas a partir de fosfito de cloridrato de dialquila

Posteriormente, descobriu-se que os fosfonatos de dialquila reagiam diretamente com aminas e tetracloreto de carbono em meio básico, de modo mais brando e com resultados igualmente satisfatórios. ${ }^{40}$ Foi desenvolvida, com pequenas modificações dos métodos de ATHERTON et al.(1945) uma nova reação de fosforilação de aminas, Esquema 5. Estas modificações melhoram os rendimentos das reações com aminoácidos e com aminas insolúveis em tetracloreto de carbono. $^{41,42}$

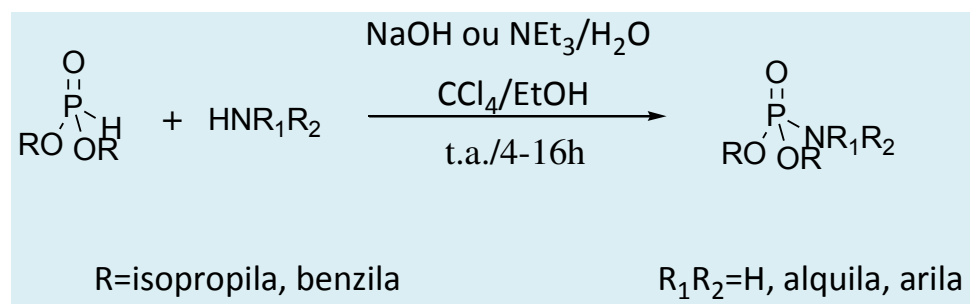

Esquema 5. Fosforilação de aminas em sistema bifásico com fosfonato de dialquila e $\mathrm{CCl}_{4}$

Os fosfonatos de dialquilas reagem suavemente com aminas primárias, secundárias ou amônia em tetracloreto de carbono para fornecer fosforoamidatos de dialquila com excelentes rendimentos. ${ }^{15}$

Uma revisão mais completa da química dos OFs e suas aplicações pode ser 
encontrada no trabalho de SANTOS e colaboradores. ${ }^{43}$

Em nosso grupo de trabalho esses compostos foram sintetizados e utilizados em diversas áreas, tanto na aplicação de diferentes doenças negligenciáveis, quanto na sua utilização como inseticidas e agentes de complexação. ${ }^{44-51}$

\section{OFs na agricultura}

A agricultura está relacionada com o cultivo de plantas e outras formas biológicas destinadas não só a produção de alimentos como também de fibras e outros produtos necessários para a vida. ${ }^{10}$

A introdução de pesticidas na agricultura ajudou a aumentar a produtividade contribuindo para a crescente produção de alimentos desde a Segunda Guerra Mundial. ${ }^{14,52}$ Os DAs no Brasil representam o segundo item mais importante para ter uma safra agrícola, ficando atrás somente dos fertilizantes. $^{3}$

Os OFs surgiram em virtude da toxicidade dos organoclorados até então utilizados, sendo o principal produto o Paration em 1944. Os compostos OFs representam mais de $36 \%$ do total do mercado mundial de pesticidas químicos, são a classe mais utilizada de pesticidas para o controle de pragas agrícolas devido à sua elevada eficácia para o controle de insetos sugadores e mastigadores, garantindo um aumento da produção agricola ${ }^{8,53-55}$.

Ao longo dos anos, muitos outros compostos OFs foram sintetizados e utilizados em grandes quantidades na agricultura, não apenas como inseticidas, mas também depois como herbicidas e em outras aplicações. Estes compostos possuem vantagens distintas no mercado de pesticidas; eles são relativamente fáceis de fazer, se biodegradam facilmente por hidrólise, de modo que os problemas de atividade residual, tão sérios com os pesticidas organoclorados, são evitados. Os compostos ativos são normalmente ésteres, amidas ou derivados de tiol de ácido fosfórico ou fosfônico. ${ }^{8,33,53,54,56}$

Os OFs são extremamente importantes para as atividades agrícolas em todo 0 mundo, compondo uma família muito diversificada de produtos químicos orgânicos com muitos usos. O uso extensivo na agricultura de produção é devido as muitas vantagens, tais como custo relativamente baixo, um largo espectro de atividade e de alto impacto sobre insetos. ${ }^{57}$ Os herbicidas são os mais utilizados, no entanto, a toxicidade deste grupo de substâncias, geralmente, é inferior a dos inseticidas. De acordo com as suas propriedades químicas, os pesticidas podem ser agrupados em 7 classes distintas, incluindo organoclorados, organofosforados, carbamatos, piretróides, aminas, anilinas e compostos heterocíclicos azotos. ${ }^{17-19} \mathrm{Na}$ Tabela 1 pode-se observar os OFs registrados no Ministério da Agricultura, Pecuária e Abastecimento (MAPA).

Estes compostos possuem uma grande diversidade de substituintes químicos e alvos bioquímicos. A quantidade de uso de inseticidas OFs está diminuindo, mas a sua importância provavelmente vai continuar por décadas, devido a sua eficiência e baixo custo. $^{58,59}$ 
Barboza, H. T. G. et al.

Tabela 1. Produtos organofosforados com registro no Ministério da Agricultura

\begin{tabular}{|c|c|c|c|}
\hline $\begin{array}{l}\text { Nome } \\
\text { Comum }\end{array}$ & Estrutura química & Nome comercial & Classe(s) \\
\hline Acefato & & Acefato Nortox & Acaricida/Inseticida \\
\hline Cadusafós & & Rugby 200 CS & $\begin{array}{c}\text { Inseticida/Nematicid } \\
\text { a }\end{array}$ \\
\hline Clorpirifós & & Clorpirifós Fersl 480 EC & $\begin{array}{c}\text { Acaricida/Formicida/ } \\
\text { Inseticida }\end{array}$ \\
\hline Diazinona & & Diazinon $600 \mathrm{CE}$ & Acaricida/Inseticida \\
\hline Dimetoato & & $\begin{array}{c}\text { Dimetoato } 500 \text { EC } \\
\text { Nortox }\end{array}$ & Acaricida/Inseticida \\
\hline Dissulfotom & & Baron/ Baysiston GR & $\begin{array}{c}\text { Acaricida/Fungicida/ } \\
\text { Inseticida }\end{array}$ \\
\hline Etiona & & Rusmite-50 & Acaricida/Inseticida \\
\hline Etoprofós & & Mocap $10 \mathrm{G}$ & $\begin{array}{c}\text { Inseticida/Nematicid } \\
\text { a }\end{array}$ \\
\hline Fenamifós & & Nemacur & Nematicida \\
\hline Fenitrotiona & & $\begin{array}{c}\text { Sumigran } 500 \mathrm{EC} / \\
\text { Pirephos EC }\end{array}$ & Formicida/Inseticida \\
\hline
\end{tabular}

Fonte:http://agrofit.agricultura.gov.br/agrofit cons/principal agrofit cons. Consultado em: 20/09/2017. 
Muitos OFs podem ser hidrolisados na presença de água ou por enzimas específicas, resultando na desintoxicação. Inseticidas OFs são, principalmente, derivados do ácido ortofosfórico ou tiofosfórico, contendo geralmente dois grupos de substituintes alcóxi e um terceiro substituinte conhecido como o "grupo de saída", este grupo é deslocado quando o OF interage com hidrolases de serina promovendo sua inibição progressiva, tendo como principal alvo a enzima AChE. A grande maioria dos OFs podem ser considerados como derivados de ácido fosfórico e incluem muitos resíduos heterocíclicos; 12 tipos de compostos heterocíclicos estão descritos como pesticidas OF. Os resíduos heterocíclicos podem determinar a sua toxicidade, mas estes grupos, tais como benzimidazol, benzotiazol, benzoxazol, e piperazina, Figura 4, exibem atividades farmacológicas versáteis e diversas como antimicrobianos, antihelmínticos, antivirais, analgésico local, e efeitos espasmolíticos. ${ }^{59,60}$<smiles>C1=CC2N=CNC2C=C1</smiles><smiles>C1=CC2N=CSC2C=C1</smiles><smiles>C1=CC2N=COC2C=C1</smiles><smiles>C1CNCCN1</smiles>

$\mathrm{H}$

\section{Benzimidazol Benzotiazol Benzoxazol Piperazina}

Figura 4. Estrutura de grupos que exibem atividades farmacológicas versáteis

O glifosato, $\mathrm{N}$-(fosfonometil) glicina, Figura 4, um herbicida sistêmico, pósemergência, de amplo espectro, é amplamente utilizado para o controle de ervas daninhas na produção agrícola, bem como em áreas urbanas, industriais e recreativas em todo o mundo. $O$ glifosato inibe a biossíntese de aminoácidos aromáticos (fenilalanina, tirosina e triptofano) e leva a vários distúrbios metabólicos, incluindo a interrupção da produção de proteínas, a biossíntese de produtos secundários e uma interrupção metabólica geral da via fenilpropanóide devido à redução em a biossíntese de aminoácidos aromáticos. ${ }^{61,62}$

O glifosato (Figura 5) é o principal ingrediente ativo presente no Roundup ${ }^{\circledR}$ (Monsanto Co., St. Louis, MO, EUA) que contém ingredientes "inerte" ou "inativo". Apesar de classificado como inócuo, a formulação comercial tem maiores efeitos colaterais do que o glifosato isolado. ${ }^{63} \mathrm{~A}$ introdução de culturas resistentes ao glifosato (Roundup Ready ${ }^{\circledR}$ ) no final da década de 1980, aumentou exponencialmente o uso de herbicidas contendo glifosato, que tem sido usado em quase todos os lugares em mais de $90 \%$ de das culturas transgênicas cultivadas no mundo. Em 1987, o glifosato foi o 170 pesticida mais usado nos Estados Unidos e, em 2001, tornou-se o herbicida mais aplicado. ${ }^{61,63}$. Em 2016 houve um aumento de 100 vezes, desde a década de 1970, na frequência e no volume de aplicações de herbicidas à base de glifosato, o que foi, em parte, responsável pelo surgimento e propagação global, como nunca visto antes, de ervas daninhas resistentes ao glifosato. ${ }^{64} \mathrm{O}$ uso do herbicida glifosato nos Estados Unidos ultrapassa o de todos os outros pesticidas OFs. 


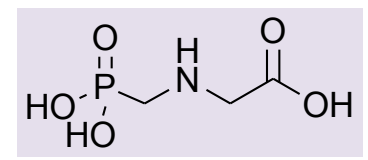

Figura 5. Estrutura do glifosato ( $\mathrm{N}$ - (fosfonometil) glicina), ingrediente ativo do Roundup ${ }^{\circledR}$.

\section{Fungicidas OFs e doenças pós- colheita}

A deterioração pós-colheita resultante de patógenos fúngicos é um grande problema que afeta não só a qualidade das frutas como também o seu valor de comercialização gerando perdas econômicas substanciais em frutas e vegetais devido a doenças póscolheita que ocorre em toda parte do mundo. Estima-se que nos países desenvolvidos, cerca de $20-25 \%$ das frutas e produtos hortícolas colhidos sejam afetados por patógenos durante o manejo pós-colheita. As espécies de Colletotrichum são patógenos de plantas economicamente importantes, especialmente em regiões tropicais, subtropicais e temperadas, onde afetam uma vasta gama de hospedeiros vegetais, infectando pelo menos 1000 espécies de plantas. A antracnose causada por Colletotrichum Gloeosporioides é uma das principais doenças pós-colheita que atinge várias culturas, dentre elas a de manga e mamão. ${ }^{65,66} \mathrm{~A}$ aplicação de pulverização generalizada de fungicidas visa reduzir este problema no entanto a crescente preocupação com a saúde ambiental e humana, tornou necessária a procura de meios alternativos para o controle de doenças. ${ }^{67,68}$ As alterações fisiológicas $e$ bioquímicas nos produtos hortifrutícolas, assim como possíveis lesões na colheita e durante o armazenamento prolongado, pode favorecer o desenvolvimento de patógenos causadores de doenças, que são uma das causas mais importantes de perdas através da cadeia de suprimentos. ${ }^{69}$

Das doenças que ocorrem em plantas, $65 \%$ delas são causadas por fungos. Os fungicidas organofosforados (OFF) foram introduzidos no final da década de 1960 para prevenir ou minimizar as perdas de culturas causadas por fungos fitopatogênicos. Embora mais de cem OFs tenham ação fungicida, estes são relativamente poucos os de uso prático. Na Tabela 2, pode-se observar alguns destes compostos. ${ }^{70}$

Um exemplo de fosfonato fungicida é o Aliette [Tris (O-etilfosfonato)de alumínio], Figura 6, comercializado em combinação com um fungicida protetor como Mikal $(50 \%$ Aliette e $25 \%$ de folpe). O Mikal é ativo contra Aternaria excoriosisepodridão negranas, presentes em culturas tropicais e nas culturas temperadas. Diferentemente dos inseticidas, a atividade dos OFFs não é devido à inibição da enzima AChE, mas a acilação de enzimas contendo grupos mercapto. Grandes progressos foram realizados nos últimos anos no desenvolvimento de diferentes tipos de fungicidas sistêmicos e sua utilidade na proteção das culturas, contudo, o desenvolvimento de resistência é de grande preocupação. Depois que o fosforotioato de S-benzilo O,O-dietilo $\quad\left(\right.$ Kitazin $\left.^{\circledR}\right)$ foi desenvolvido como um novo fungicida para brusone no arroz, vários OFs foram colocados em campo para controlar esta doença. ${ }^{37}$ 
Tabela 2. OFFs utilizados na agricultura

\begin{tabular}{|c|c|c|c|c|c|}
\hline $\begin{array}{l}\text { Nome } \\
\text { comum }\end{array}$ & Grupo químico & $\begin{array}{l}\text { Estrutura } \\
\text { química }\end{array}$ & Modo de ação & Fungos & Culturas \\
\hline $\begin{array}{l}\text { Fosetil } \\
\text { (Aliette) }\end{array}$ & Fosfonato & & $\begin{array}{l}\text { Inibição do } \\
\text { crescimento } \\
\text { do micélio e } \\
\text { redução da } \\
\text { formação de } \\
\text { esporos }\end{array}$ & $\begin{array}{c}\text { Phitophthora } \\
\text { e Pythium }\end{array}$ & $\begin{array}{c}\text { Abacaxi, } \\
\text { Café, } \\
\text { Citros, } \\
\text { maçã, } \\
\text { uva }\end{array}$ \\
\hline Edifenfós & $\begin{array}{l}\text { Fosforotioato } \\
\text { de arila }\end{array}$ & & $\begin{array}{c}\text { Inibição da } \\
\text { biossíntese de } \\
\text { fosfatidilcolina }\end{array}$ & $\begin{array}{l}\text { Pyricularia } \\
\text { oryzae, } \\
\text { Fusarium }\end{array}$ & Arroz \\
\hline $\begin{array}{c}\text { Dissulfoto } \\
\mathrm{m}\end{array}$ & $\begin{array}{c}\text { Fofosforotiona } \\
\text { to }\end{array}$ & & $\begin{array}{c}\text { Inibição da } \\
\text { AChE }\end{array}$ & $\begin{array}{c}\text { Hemileia } \\
\text { vastatrix, } \\
\text { Leucoptera } \\
\text { coffeella }\end{array}$ & $\begin{array}{c}\text { Café, } \\
\text { algodão, } \\
\text { milho, } \\
\text { batata. }\end{array}$ \\
\hline $\begin{array}{c}\text { Tolclofos- } \\
\text { metil }\end{array}$ & $\begin{array}{c}\text { Fofosforotiona } \\
\text { to }\end{array}$ & & $\begin{array}{l}\text { Inibição da } \\
\text { biossíntese de } \\
\text { fosfolipídeos }\end{array}$ & $\begin{array}{c}\text { Thanatephoru } \\
\text { s cucumeris, } \\
\text { Athelia rolfsii }\end{array}$ & $\begin{array}{l}\text { Batata e } \\
\text { algodão }\end{array}$ \\
\hline Pirazofós & $\begin{array}{l}\text { Fosforotioato } \\
\text { de heterociclo }\end{array}$ & & $\begin{array}{l}\text { Previne a } \\
\text { formação do } \\
\text { apresório do } \\
\text { conidio. }\end{array}$ & $\begin{array}{l}\text { Phomopsis } \\
\text { viticola, } \\
\text { Glomerella } \\
\text { cingulata, } \\
\text { Greeneria } \\
\text { uvicola }\end{array}$ & $\begin{array}{c}\text { Abóbora } \\
\text {, feijão- } \\
\text { vagem, } \\
\text { maçã, } \\
\text { melanci } \\
\text { a, } \\
\text { melão, } \\
\text { pepino, } \\
\text { trigo e } \\
\text { uva }\end{array}$ \\
\hline Iprobenfos & Fosforotiolato & & $\begin{array}{c}\text { Inibição da } \\
\text { crescimento } \\
\text { micelial e de } \\
\text { melanina }\end{array}$ & $\begin{array}{c}\text { Pyricularia } \\
\text { oryzae }\end{array}$ & Arroz \\
\hline
\end{tabular}

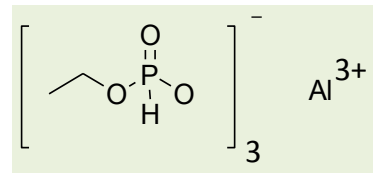

Figura 6. Fungicida foliar não sistêmico Aliette comumente usado na agricultura

Alguns estudos recentes mostram que, ao sintetizar moléculas orgânicas, a incorporação de fósforo pode ser projetada de modo a reduzir a toxicidade sem comprometimento da sua atividade como DA. Uma das propriedades úteis dos 
compostos de fósforo é a sua estabilidade relativamente baixa e a degradação metabólica rápida nas plantas, nos organismos dos animais, no solo e em outros componentes do ambiente, com a formação de produtos seguros para seres humanos e animais domésticos. Outra característica importante desses compostos é a alta seletividade de sua ação. ${ }^{30}$

\section{OFs e inibição da enzima AChE}

A acetilcolinesterase (AChE), como um dos principais membros da família da enzima colinesterase, desempenha um papel vital em uma série de áreas importantes, incluindo neurobiologia, toxicologia e farmacologia. ${ }^{71} \mathrm{AAChEou}$ acetilcolina acetilhidrolase, é uma enzima pertencente à família das colinesterases, responsável pela finalização da transmissão dos impulsos nervosos nas sinapses colinérgicas através da hidrólise da acetilcolina (ACh), principal neurotransmissor do sistema nervoso central dos insetos, Esquema 6.A AChE do inseto é um dímero globular dissulfureto, existente em diferentes variações alélicas. A inibição de sua atividade pode induzir mudanças no sitio ativo da enzima, levando ao acúmulo de ACh dentro das sinapses interrupção do sinal de transmissão. ${ }^{6} \mathrm{~A}$ principal toxicidade de alguns OFs é atribuída à sua capacidade de inibir a atividade da AChE, devido ao fato desta enzima estar presente também em mamíferos. Essa inibição impede a quebra da ACh nas sinapses colinérgicas, o que pode afetar severamente o sistema nervoso humano. A ACh é um importante neurotransmissor que medeia a contração muscular no músculo esquelético e liso, a estimulação pré-ganglionar no sistema nervoso autónomo (simpático e parassimpático), e a estimulação pósganglionar no sistema parassimpático. Estas ações da ACh resultam, classicamente, na ativação de receptores nicotínicos (nos gânglios autônomos e músculo esquelético) e de receptores muscarínicos (no miocárdio, glândulas exócrinas e músculo liso). ${ }^{72-74}$

A inibição da enzima, mostrada no Esquema 7, impede que ela desempenhe seu papel essencial de hidrolisar a ACh, cujo acúmulo gera superestimulação de receptores nicotínicos e muscarínicos em ambos os sistemas nervosos central e periférico levando a sintomas graves na vítima (incluindo a morte). ${ }^{75,76} \mathrm{~A}$ ligação do OF com AChE leva à fosforilação da enzima e esta reação não é facilmente reversível. A AChE fosfatada é relativamente estável e, dependendo dos grupos ligados ao átomo de fósforo, torna-se irreversivelmente inibida. A taxa de reativação espontânea de AChE é muito lenta com OF de dietila enquanto é relativamente rápida com $\mathrm{OFs}$ de dimetila. $\mathrm{A}$ terapia moderna utiliza compostos que possuem o grupo oxima capaz de reativar enzimas inibidas por um ataque nucleofílico na serina fosfatada. No entanto, há envelhecimento da enzima fosforilada, e uma vez que a enzima envelhece, esta não pode mais ser reativada por oximas. Substituição de um átomo de oxigênio do OF pelo de enxofre conduz à formação de compostos organotiofosfórico, como clorpirifós, malation e paration, que possuem menor potencial letal. ${ }^{76,77}$

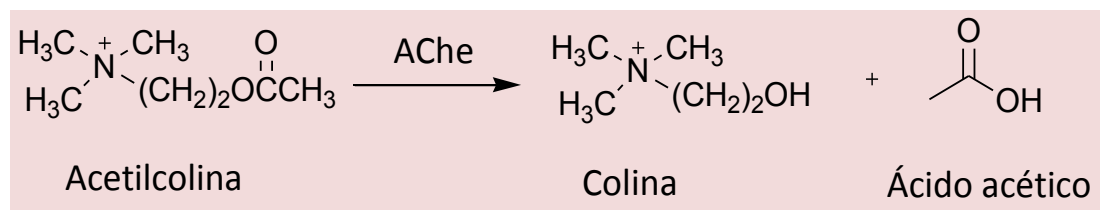

Esquema 6. Hidrólise da Ach pela AChE

Após a inibição da AChE por OF dois envelhecimento da enzima ou a reativação processos podem acontecer: o espontânea da enzima (Esquema 8), podendo 
ser acelerada por várias ordens de grandeza com adição de um nucleófilo forte como a oxima. No entanto, a reação de reativação para a maioria dos complexos AChE-OF, sem a presença de oximas, ocorre a uma taxa insignificante, sendo portanto a reação de envelhecimento majoritária. ${ }^{78}$

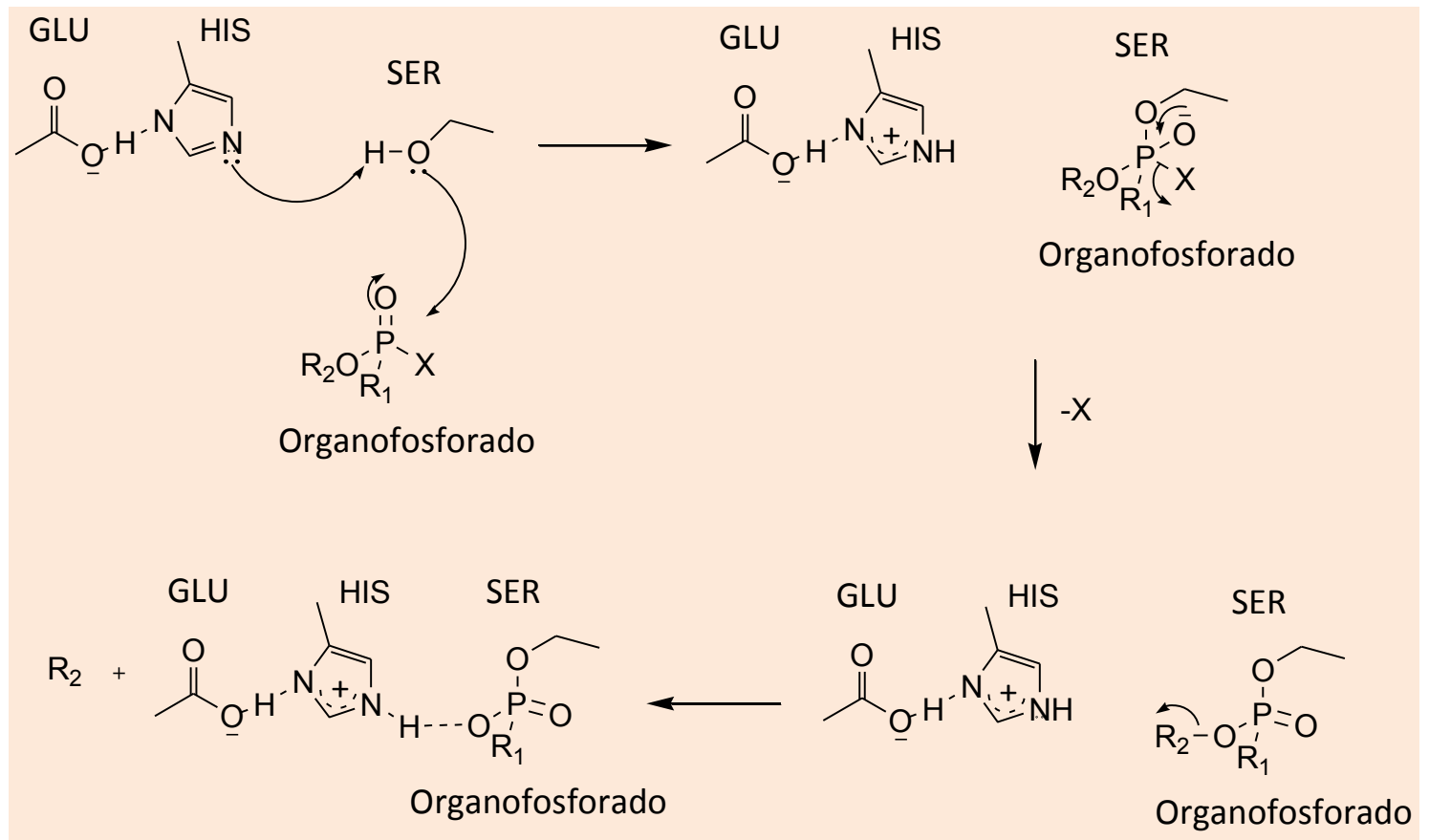

Esquema 7. Mecanismo clássico de inibição da AChE por inseticidas organofosforados.
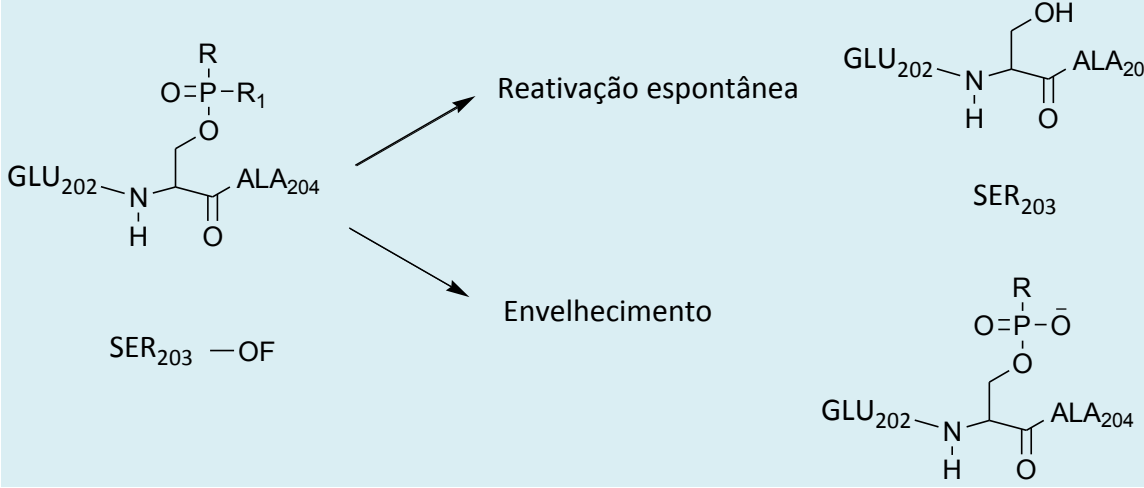

Esquema 8. Esquema da Reativação espontânea e do Envelhecimento, sendo, R o grupo alquil, O-alquil ou amida; R1 o grupo O-alquil ou amida

A fim de reverter os efeitos tóxicos dos OFs, medidas terapêuticas adicionais são indispensáveis. A desfosforilação da serina do sítio ativo da AChE é chamada reativação, e é considerado o principal mecanismo de ação das oximas, Esquema 9. 


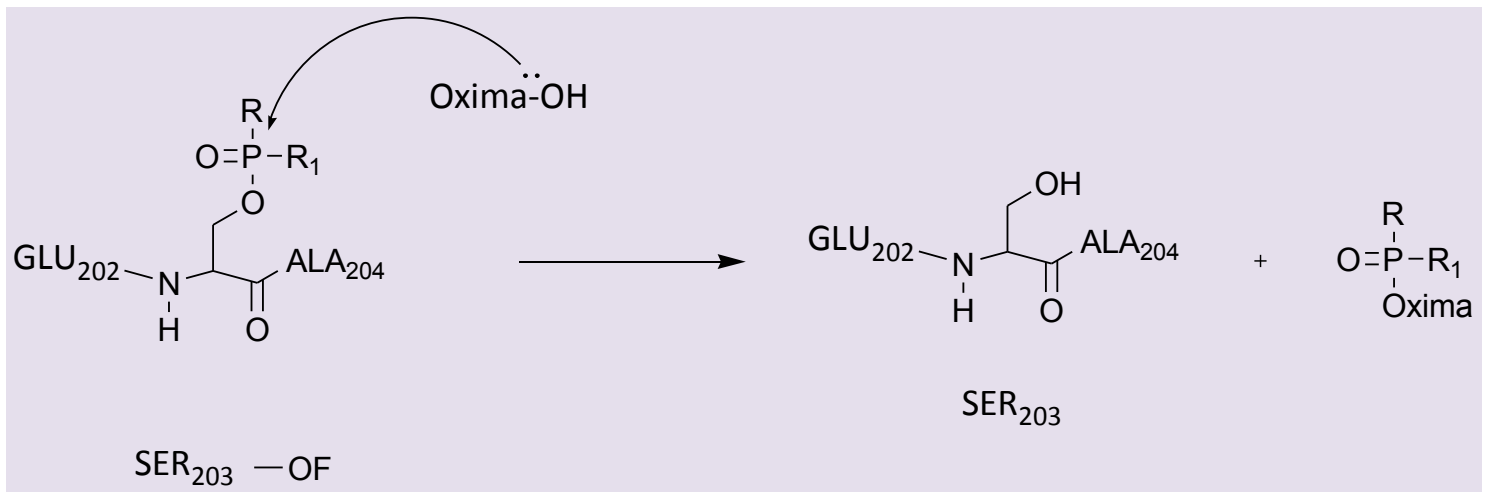

Esquema 9. Reação de reativação do conjugado AChE-OP por uma oxima, sendo $R$ o grupo alquil, O-alquil ou amida; $\mathrm{R}_{1}$ o grupo $\mathrm{O}$-alquil ou amida

A Organização Mundial da Saúde informa que existem cerca de três milhões de casos por ano de intoxicação com pesticidas OF no mundo, no entanto, essas intoxicações geralmente resultam de abusos de pesticidas ou tentativas suicidas. ${ }^{77}$

A AChE tem sido utilizada como um biomarcador importante de muitas doenças associadas ao neurotransmissor além de ser usada para detectar potenciais drogas e diagnosticar envenenamento por agentes de combate químico e pesticidas. ${ }^{71}$ As mudanças na atividade de AChE foram usadas como biomarcador de neurotoxicidade e descritas em espécies de insetos como consequência de ações de inseticidas e biopesticidas. ${ }^{6}$

\section{Potenciais dos OFs}

OFs inibidores da AchE estão sendo desenvolvidos com intuito de atuarem como fármacos. Ainda na área medicinal, os compostos OFs têm sido destaque nas últimas décadas, apresentando ação contra as mais variadas patologias. Como exemplo, pode-se citar os bisfosfonatos, que têm sido utilizados com sucesso no tratamento de doenças ósseas, assim como alguns fosforamidatos e fosfatos, que têm apresentado ação eficaz como antiretrovirais. Alguns OFs têm sido usados como agentes anti-helmínticos em animais domésticos. Estes compostos afetam parasitas por acumulação da Ach atribuídos a inibição
AChE, conduzindo à interferência com a transmissão neuromuscular e, subsequentemente, a paralisia, seguido de expulsão de parasitas do corpo do animal. ${ }^{79}$

Para além destas aplicações, recentemente se tem dado atenção a doença de Alzheimer ( $A D)$, também chamada de demência pré-antil, é uma doença degenerativa do sistema nervoso central caracterizada por neurodegeneração progressiva, que ocorre principalmente durante a fase pré-senil e a senilidade, com várias manifestações clínicas, incluindo dismesia, transtorno comportamental, mudança de personalidade e distúrbios emocionais, e assim por diante. Pesquisa atuais mostram que a patogênese de $A D$ não foi esclarecida, e acredita-se que $A D$ é uma doença multi-patogênica. Existem muitas hipóteses sobre a causa da $A D$, sendo a hipótese colinérgica uma das mais aceitas no momento. Assim, estudos mais extensos sobre drogas anti-AD são relacionados a inibidores de acetilcolinesterase $(\mathrm{AChE})^{80}$. AD é marcado pela diminuição das concentrações de ACh no córtex cerebral principalmente devido a disfunção e perda de neurônios colinérgicos. Esta situação é ainda agravada pela presença de AChE na fenda sináptica por conta da hidrólise da ACh. Para melhorar as diminuições cognitivas em $A D$, os inibidores de AChE são clinicamente prescritos em quantidade moderada. Estes podem competir com ACh para ligação no sitio ativo do AChE e assim limitar a taxa de ACh hidrolisada. Dessa forma pode-se manter 
a quantidade de ACh disponível nos receptores pós-sinápticos para a potencialização a longo prazo, que é sinônimo de aprendizado e memória. ${ }^{78,81}$

\section{Referências Bibliográficas}

${ }^{1}$ Figueiredo, P. N. New challenges for public research organisations in agricultural innovation in developing economies: Evidence from Embrapa in Brazil's soybean industry. The Quarterly Review of Economics and Finance 2016, 62, 21. [CrossRef]

${ }^{2}$ Ytoshi, F.; Mackenzie, S.; Giro, R.; Mackenzie, M.; Roberto, M.; Santos, D. O. S. A logística reversa e as embalagens vazias de defensivos agrícolas no Brasil, 2010. [Link]

${ }^{3}$ Silva, M. F. de O. e; Costa, L. M. da A indústria química e o setor de fertilizantes 2012. [Link]

${ }^{4}$ Gerhardt, C.; Wiest, J. M.; Girolometto, G.; Silva, M. A. S. da; Weschenfelder, S. Aproveitamento da casca de citros na perspectiva de alimentos: prospecção da atividade antibacteriana. Brazilian Journal of Food Technology 2012, 15, 11. [CrossRef]

${ }^{5}$ Porto, M. F.; Soares, W. L. Modelo de desenvolvimento, agrotóxicos e saúde: um panorama da realidade agrícola brasileira e propostas para uma agenda de pesquisa inovadora. Revista Brasileira de Saúde Ocupacional 2012, 37, 17. [CrossRef]

${ }^{6}$ Mrdaković, M.; Ilijin, L.; Vlahović, M.; Matić, D.; Gavrilović, A.; Mrkonja, A.; PerićMataruga, V. Acetylcholinesterase (AChE) and heat shock proteins (Hsp70) of gypsy moth (Lymantria dispar L.) larvae in response to long-term fluoranthene exposure. Chemosphere 2016, 159, 565. [CrossRef]

${ }^{7}$ Guiloski, I. C.; Silva, E. G. da; Nishikawa, C. M.; Silva de Assis, H. C. da Atividade da colinesterase em cérebro e músculo de Corydoras paleatus (Pisces, Teleostei) expostos ao carbaril. Revista Acadêmica: Ciências Agrárias e Ambientais 2010, 8, 461. [Link]

${ }^{8}$ Filho, E. L. B. Impactos Ambientais Ocasionados pelo Uso de Defensivos
Agrícolas: a Escassez de Pesquisas no Programa Nacional de Pesquisa Agropecuária Brasileiro. XLII Congresso da Sociedade Brasileira de Economia e Sociologia Rural 2004, 20. [Link]

${ }^{9}$ Barboza, H. T. G.; Soares, A. G.; Fonseca, M. J. de O.; DaCosta, J. B. N.; Sarquis, M. I. de M. Teste de Inibição da Enzima Acetilcolinesterase de Compostos Organofosforados com Potencial Ação Fungicida na Cultura de Mamão (Carica papaya L.) Rio de Janeiro, RJ, 2010. [Link]

${ }^{10}$ Silva, M. F. O.; Costa, L. M. A indústria de defensivos agrícolas. Cad. BNDS Setorial 2011, 35, 233. [Link]

${ }^{11}$ Silva, M. F. O.; Costa, L. M. A indústria de defensivos agrícolas. BNDS Setorial 2012, 233. [Link]

12 Londres, F. Agrotóxicos no Brasil-um guia para ação em defesa da vida 2011. [Link]

${ }^{13}$ Oliveira, A. H. B.; Cavalcante, R. M.; Duaví, W. C.; Fernandes, G. M.; Nascimento, R. F.; Queiroz, M. E. L. R.; Mendonça, K. V The legacy of organochlorine pesticide usage in a tropical semi-arid region (Jaguaribe River, Ceará, Brazil): Implications of the influence of sediment parameters on occurrence, distribution and fate. Science of the Total Environment 2016, 542, 254. [CrossRef]

${ }^{14}$ Mee Kin, C.; Guan Huat, T. Headspace solid-phase microextraction for the evaluation of pesticide residue contents in cucumber and strawberry after washing treatment. Food Chemistry 2010, 123, 760. [CrossRef]

${ }^{15}$ Barboza, H. T. G. Síntese de novas fosforilidrazonas heterocíclicas para controle de patógenos pós-colheita de mamão (Carica papaya L.)., Universidade Federal Rural do Rio de Janeiro, 2010.[Link]

${ }^{16}$ Saoudi, A.; Fréry, N.; Zeghnoun, A.; Bidondo, M.-L.; Deschamps, V.; Göen, T.; Garnier, R.; Guldner, L. Serum levels of organochlorine pesticides in the French adult population: the French National Nutrition and Health Study (ENNS), 2006-2007. Science of the Total Environment 2014, 472, 1089. [CrossRef] [PubMed]

${ }^{17}$ Ribas, P. P.; Matsumura, A. T. S. A química dos agrotóxicos: impacto sobre a saúde e 
meio ambiente. Revista Lib. Novo Hamburgo 2009, 10, 149. [Link]

${ }^{18}$ Zheng, S.; Chen, B.; Qiu, X.; Chen, M.; Ma, Z.; $Y$ U,$X$. Distribution and risk assessment of 82 pesticides in Jiulong River and estuary in South China. Chemosphere 2016, 144, 1177. [CrossRef] [PubMed]

${ }^{19}$ Oliveira-Silva, J. J.; Alves, S. R.; Meyer, A.; Perez, F.; Sarcinelli, P. de N.; Mattos, R. de C. O. da C.; Moreira, J. C. Influência de fatores socioeconômicos na contaminação por agrotóxicos, Brasil. Revista de Saude Pública 2001, 35, 130. [CrossRef]

${ }^{20}$ Alfonso, L.-F.; Germán, G. V.; Carmen, P. C. M. del; Hossein, G. Adsorption of organophosphorus pesticides in tropical soils: The case of karst landscape of northwestern Yucatan. Chemosphere 2017, 166, 292. [CrossRef]

${ }^{21}$ Zhou, Q.; Li, J.; Wang, B.; Wang, S.; Li, H.; Chen, J. Selectivity improvement of positive photoionization ion mobility spectrometry for rapid detection of organophosphorus pesticides by switching dopant concentration. Talanta 2018, 176, 247. [CrossRef]

${ }^{22}$ Cequier, E.; Sakhi, A. K.; Haug, L. S.; Thomsen, C. Exposure to organophosphorus pesticides in Norwegian mothers and their children: Diurnal variability in concentrations of their biomarkers and associations with food consumption. Science of the Total Environment 2017, 590-591, 655. [CrossRef]

${ }^{23}$ González-curbelo, M. Á.; Socas-rodríguez, B.; Herrero, M.; Herrera-herrera, A. V; Hernández-borges, J. Dissipation kinetics of organophosphorus pesticides in milled toasted maize and wheat flour ( gofio ) during storage. Food Chemistry 2017, 229, 854. [CrossRef]

${ }^{24}$ Xie, H.; Bei, F.; Hou, J.; Ai, S. A highly sensitive dual-signaling assay via inner filter effect between g-C $3 \quad \mathrm{~N} \quad 4$ and gold nanoparticles for organophosphorus pesticides. Sensors Actuators B: Chemical 2017. [CrossRef]

${ }^{25}$ Oliveira, C. M.; Auad, A. M.; Mendes, S. M.; Frizzas, M. R. Crop losses and the economic impact of insect pests on Brazilian agriculture. Crop Protection 2014, 56, 50. [CrossRef]
${ }^{26}$ Santos, G. R. dos Características, Sistema de Registros de Produtos e Concorrência no Mercado de Agrotóxicos no Brasil. Radar 2012, 7. [Link]

${ }^{27}$ Bueno, P. C. O impacto do consumo de agrotóxicos na prevalência de desfechos perinatais no Brasil, Universidade Federal do Rio de Janeiro, 2014. [Link]

${ }^{28}$ Sitio do Ministério do Meio Ambiente. Disponível em:< http://www.mma.gov.br/seguranca-

quimica/agrotoxicos> Acesso em: 25 setembro 2017.

[Linkhttps://doi.org/10.1016/i.proeng.2016.0 2.087]

${ }^{29}$ Weferling, N.; Zhang, S. M.; Chiang, C. H. Commercial Organophosphorus Chemicals: Status and New Developments. Procedia Engineering 2016, 138, 291. [CrossRef]

${ }^{30}$ Chaturvedi, K.; Kumar, A.; Mishra, A. Synthesis, antibacterial and antifungal properties of novel organophosphorus compounds. 2014, 6, 27. [Link]

${ }^{31}$ Eleršek, T.; Filipi, M.; Pesticides - The Impacts of Pesticides Exposure., Vol 12, 243, 2016. [CrossRef]

${ }^{32}$ Joshi, P. R.; Ramanathan, N.; Sundararajan, K.; Sankaran, K. Gas phase reaction of phosphorus trichloride and methanol: Matrix isolation infrared and DFT studies. Journal of Molecular Structure 2015, 1100, 80. [CrossRef]

${ }^{33}$ Mazzacurati, M.; Tese de doutorado, Università di Bologna, 2007. [Link]

${ }^{34} \mathrm{Li}, \mathrm{C}$.; Chen, T.; Han, L.-B. Iron-Catalyzed Clean Dehydrogenative Coupling of Alcohols with $\mathrm{P}(\mathrm{O})-\mathrm{H}$ Compounds: a New Protocol for ROH Phosphorylation. Dalton Transactions 2016, 45, 14893. [CrossRef]

${ }^{35}$ Cotton, F. A.; Wilkinson, G. Advanced Inorganic Chemistry, 5tha. ed, Wiley: New York, 1988.

${ }^{36}$ Xiong, B.; Zhou, Y.; Zhao, C.; Goto, M.; Yin, S.-F.; Han, L.-B. Systematic study for the stereochemistry of the Atherton-Todd reaction. Tetrahedron 2013, 69, 9373. [CrossRef]

${ }^{37}$ Adelowo, F. E. Synthesis, Characterization and Fungicidal Activity of Some Dialkyl Alkylphosphonates and Dialkyl Phenylphosphonates. International Journal of 
Research and Reviews in Applied Sciences 2012, 12, 107. [Link]

${ }^{38}$ Kornev, A. N.; Zolotareva, N. V.; Sushev, V. V.; Cherkasov, A. V.; Abakumov, G. A. Interaction of phosphorus trichloride with triethylamine. Mendeleev Communications 2015, 25, 236. [CrossRef]

${ }^{39}$ Nogueira, A. J. M.; Dissertação de mestrado, Universidade Federal Rural do Rio de Janeiro, 2007. [Link]

${ }^{40}$ Atherton, F. R.; Openshaw, H. T.; Todd, A. R. Studies on phosphorylation. Part II. The reaction of dialkyl phosphites with polyhalogen compounds in presence of bases. A new method for the phosphorylation of amines. Journal of Chemical Society 1945, 660. [CrossRef]

${ }^{41} \mathrm{Ji}$, G. J.; Xue, C. B.; Zeng, J. N.; Li, L. P.; Chai, W. G.; Zhao, Y. F. Synthesis of N(Diisopropyloxyphosphoryl)amino Acids and Peptides. Synthesis 1988, 6, 444. [CrossRef]

${ }^{42}$ Zhao, Y. F.; Xi, S. K.; Song, A. T.; Ji, G. J. Phosphoryl as a novel amino protecting group for Friedel-Crafts acylation of $\mathrm{N}$-[2(3,4-dialkoxyphenyl)ethyl]glycine. The Journal of the Organoc Chemistry 1984, 49, 4549. [CrossRef]

${ }^{43}$ Santos, V. M. R. dos; Donnici, C. L.; DaCosta, J. B. N.; Caixeiro, J. M. R. Organophosphorus Pentavalent Compounds: History, Synthetic Methods of Preparation and Application as Insecticides and Antitumor Agents. Química Nova 2007, 30, 159. [CrossRef]

${ }^{44}$ Lin, W. O.; Souza, M. C. de; DaCosta, J. B. N. uímica de Organofosforados. X: Síntese de NDialquilfosforil-Guanidinas, Uréias e Tiouréias. Química Nova 1995, 18, 431. [Link]

${ }^{45}$ Rodrigues, J. M.; DaCosta, J. B. N. Synthesis and Characterization of New Symmetrical Bisphosphonates. Phosphorus, Sulfur, and Silicon and the Related Elements 2002, 177, 137. [CrossRef]

${ }^{46}$ dos Santos, V. M. R.; DaCosta, J. B. N.; Sant'Anna, C. M. R.; Oliveira, M. C. C. Synthesis, characterization, molecular modeling and biological activity against Artemia Salina of new symmetrical bisphosphoramidates. Phosphorus, Sulfur, and Silicon and the Related Elements 2004,
179, 173. [CrossRef]

${ }^{47}$ Santos, V. M. R. dos; Sant'Anna, C. M. R.; Moya Borja, G. E.; Chaaban, A.; Côrtes, W. S.; DaCosta, J. B. N. New bisphosphorothioates and bisphosphoroamidates: Synthesis, molecular modeling and determination of insecticide and toxicological profile. Bioorganic Chemistry 2007, 35, 68. [CrossRef] ${ }^{48}$ Rodrigues, J. M.; Sant'Anna, C. M.; Rumjanek, V. M.; da Costa, J. B. N. Diastereoselective Synthesis of New Dialkylphosphorylhydrazones. Phosphorus, Sulfur, and Silicon and the Related Elements 2010, 185, 40. [Link]

${ }^{49}$ da Matta, C. B. B.; de Queiroz, A. C.; Santos, M. S.; Alexandre-Moreira, M. S.; Gonçalves, V. T.; Del Cistia, C. de N.; Sant'Anna, C. M. R.; DaCosta, J. B. N. Novel dialkylphosphorylhydrazones: Synthesis, leishmanicidal evaluation and theoretical investigation of the proposed mechanism of action. European Journal of Medicinal Chemistry 2015, 101, 1. [CrossRef] [PubMed] ${ }^{50}$ dos Anjos, D. O.; Sobral Alves, E. S.; Gonçalves, V. T.; Fontes, S. S.; Nogueira, M. L.; Suarez-Fontes, A. M.; Neves da Costa, J. B.; Rios-Santos, F.; Vannier-Santos, M. A. Effects of a novel $\beta$-lapachone derivative on Trypanosoma cruzi : Parasite death involving apoptosis, autophagy and necrosis. International Journal for Parasitology - Drugs and Drug Resistance 2016, 6, 207. [CrossRef] [PubMed]

${ }^{51}$ Barboza, H. T. G.; Soares, A. G.; Zampirolli, L. S.; Nogueira, A. J. M.; DaCosta, J. B. N. Síntese e Caracterização de Novas fosforilidrazonas com potencial atividade fungicida. Sociedade Brasileira de Química 2004, 1. [Link]

${ }^{52}$ Carvalho, N. L.; Pivoto, T. S. Ecotoxicologia: conceitos, abrangência e importância agronômica. Revista Eletrônica do PPGEAmbCCR//UFSM 2011, 2, 176. [Link]

${ }^{53}$ Shapiro, G. D.; Dodds, L.; Arbuckle, T. E.; Ashley-Martin, J.; Ettinger, A. S.; Fisher, M.; Taback, S.; Bouchard, M. F.; Monnier, P.; Dallaire, R.; Morisset, A.-S.; Fraser, W. Exposure to organophosphorus and organochlorine pesticides, perfluoroalkyl substances, and polychlorinated biphenyls in 
pregnancy and the association with impaired glucose tolerance and gestational diabetes mellitus: The MIREC Study. Environmental Research 2016, 147, 71. [CrossRef] [PubMed]

${ }^{54}$ Yan, X.; Li, H.; Han, X.; Su, X. A ratiometric fluorescent quantum dots based biosensor for organophosphorus pesticides detection by inner-filter effect. Biosensors and Bioelectronics 2015, 74, 277. [CrossRef] [PubMed]

${ }^{55}$ Zhang, Y.-H.; Xu, D.; Liu, J.-Q.; Zhao, X.-H. Enhanced degradation of five organophosphorus pesticides in skimmed milk by lactic acid bacteria and its potential relationship with phosphatase production. Food Chemistry 2014, 164, 173. [CrossRef] [PubMed]

${ }^{56}$ Zhang, B.; Huang, W.; Li, J.; Zhao, C.; Fan, S.; Wu, J.; Liu, C. Principles, developments and applications of computer vision for external quality inspection of fruits and vegetables: A review. Food Research International 2014, 62, 326. [CrossRef]

${ }^{57}$ Casida, J. E.; Quistad, G. B. Serine hydrolase targets of organophosphorus toxicants. Chemico-Biological Interactions 2005, 157158, 277. [CrossRef] [PubMed]

${ }^{58}$ Chen, W.; Liu, Y.; Jiao, B. Dissipation behavior of five organophosphorus pesticides in kumquat sample during honeyed kumquat candied fruit processing. Food Control 2016, 66, 87. [CrossRef]

${ }^{59}$ Güngördü, A.; Sireci, N.; Küçükbay, H.; Birhanli, A.; Ozmen, M. Evaluation of in vitro and in vivo toxic effects of newly synthesized benzimidazole-based organophosphorus compounds. Ecotoxicology and Environmental Safety 2013, 87, 23. [CrossRef] [PubMed]

${ }^{60}$ Marsillach, J.; Hsieh, E. J.; Richter, R. J.; MacCoss, M. J.; Furlong, C. E. Proteomic analysis of adducted butyrylcholinesterase for biomonitoring organophosphorus exposures. Chemico-Biological Interactions 2013, 203, 85. [CrossRef] [PubMed]

${ }^{61}$ Martin, D. E.; Latheef, M. A. Efficacy of electrostatically charged glyphosate on ryegrass. Journal of Electrostatics 2017, 90. [CrossRef]

${ }^{62}$ Fan, L.; Feng, Y.; Weaver, D. B.; Delaney, D. P.; Wehtje, G. R.; Wang, G. Glyphosate effects on symbiotic nitrogen fixation in glyphosate-resistant soybean. Applied Soil Ecology 2017, 121, 11. [CrossRef]

${ }^{63}$ Bridi, D.; Altenhofen, S.; Gonzalez, J. B.; Reolon, G. K.; Bonan, C. D. Glyphosate and Roundup ${ }^{\circledR}$ alter morphology and behavior in zebrafish. Toxicology 2017, 392, 32. [CrossRef]

${ }^{64}$ Myers, J. P.; Antoniou, M. N.; Blumberg, B.; Carroll, L.; Colborn, T.; Everett, L. G.; Hansen, M.; Landrigan, P. J.; Lanphear, B. P.; Mesnage, R.; Vandenberg, L. N.; vom Saal, F. S.; Welshons, W. V.; Benbrook, C. M. Concerns over use of glyphosate-based herbicides and risks associated with exposures: a consensus statement. Environmental Health 2016, 15, 19. [CrossRef] [PubMed]

${ }^{65}$ Xu, X.; Lei, H.; Ma, X.; Lai, T.; Song, H.; Shi, $X . ; \quad L i, \quad J$. Antifungal activity of 1methylcyclopropene (1-MCP) against anthracnose (Colletotrichum gloeosporioides) in postharvest mango fruit and its possible mechanisms of action. International Journal of Food Microbiology 2017, 241, 1. [CrossRef] ${ }^{66}$ Bonett, L. P.; Almeida, M.; Aquino, T. F. De; Bernardi-wenzel, J. Caracterização morfocultural e infecção cruzada de Colletotrichum gloeosporioides agente causal da antracnose de frutos e hortaliças em póscolheita. Ambiência 2010, 6, 451. [Link]

${ }^{67}$ Li, J.; Lei, H.; Song, H.; Lai, T.; Xu, X.; Shi, X. 1-methylcyclopropene (1-MCP) suppressed postharvest blue mold of apple fruit by inhibiting the growth of Penicillium expansum. Postharvest Biology and Technology 2017, 125, 59. [CrossRef]

${ }^{68}$ Yang, Q.; Wang, H.; Zhang, H.; Zhang, X.; Apaliya, M. T.; Zheng, X.; Mahunu, G. K. Effect of Yarrowia lipolytica on postharvest decay of grapes caused by Talaromyces rugulosus and the protein expression profile of $\mathrm{T}$. rugulosus. Postharvest Biology and Technology 2017, 126, 15. [CrossRef]

${ }^{69}$ Cerrillo, J. L.; Palomares, A. E.; Rey, F.; Valencia, S.; Palou, L.; Pérez-Gago, M. B. Agzeolites as fungicidal material: Control of citrus green mold caused by Penicillium digitatum. Microporous and Mesoporous Materials 2017, 254, 69. [CrossRef]

${ }^{70}$ Nagaraju, P. M.; Bhargavi, S. M.; Praveen, 
U. S.; Kemparaju, K. Separation of Ditalimfos organophosphorus fungicide in adsorption thin layer chromatography and reverse phase high performance thin layer chromatograph. Journal of Chemical and Pharmaceutical Research 2013, 5, 231. [Link]

${ }^{71}$ Xu, J.; Zhou, F.; Chen, L.; Chen, G.; Pan, S.; Qian, Z.; Feng, H. Thiol-triggered disaggregation-induced emission controlled by competitive coordination for acetylcholinesterase monitoring and inhibitor screening. Sensors Actuators B: Chemical 2018, 255, 22. [CrossRef]

${ }^{72}$ Silva, S. M. S. da Intoxicações por inibidores da acetilcolinesterase: etiologia, diagnóstico e tratamento, Faculdade de Medicina da Universidade de Coimbra, 2015. [Link]

${ }^{73}$ Akıner, M. M. Malathion and Propoxur Resistance in Turkish Populations of the Anopheles maculipennis Meigen (Diptera: Culicidae) and Relation to the Insensitive Acetylcholinesterase. Turkiye Parazitoloji Dergisi 2014, 38, 111. [CrossRef] [PubMed]

${ }^{74}$ Tan, M. J.; Hong, Z. Y.; Chang, M. H.; Liu, C. C.; Cheng, H. F.; Loh, X. J.; Chen, C. H.; Liao, C. D.; Kong, K. V. Metal carbonyl-gold nanoparticle conjugates for highly sensitive SERS detection of organophosphorus pesticides. Biosensors and Bioelectronics 2017, 96, 167. [CrossRef]

${ }^{75}$ Comim, C. M.; Moraz, T.; Abreu, I.; Fraga, D. B.; Ghedim, F. V.; Mildner, N.; Tuon, L.; Vainzof, M.; Zugno, A. I.; Quevedo, J. Reduction of acethylcolinesterase activity in the brain of $\mathrm{mdx}$ mice. Neuromuscular Disorders 2011, 21, 359. [CrossRef]
${ }^{76}$ Arora, S.; Balotra, S.; Pandey, G.; Kumar, A. Binary combinations of organophosphorus and synthetic pyrethroids are more potent acetylcholinesterase inhibitors than organophosphorus and carbamate mixtures: An in vitro assessment. Toxicology Letters 2017, 268, 8. [CrossRef] [PubMed]

${ }^{77}$ Bušić, V.; Katalinić, M.; Šinko, G.; Kovarik, Z.; Gašo-Sokač, D. Pyridoxal oxime derivative potency to reactivate cholinesterases inhibited by organophosphorus compounds. Toxicology Letters 2016, 262, 114. [CrossRef]

${ }^{78}$ Matos, K. S. Aspectos moleculares da reativação da acetilcolinesterase inibida por ciclosarin e carbofurano, Universidade Federal de Lavras, 2012. [Link]

${ }^{79}$ Barboza, H. T. G.; DaCosta, J. B. N.; Soares, A. G.; Sarquis, M. I. de M.; Freitas-Silva, O.; Lira, A. F.; Alcântara, I. Em Revisão Anual de Patologia de Plantas-RAPP 2013. [Link]

${ }^{80}$ Chen, H. W.; He, X. H.; Yuan, R.; Wei, B. J.; Chen, Z.; Dong, J. X.; Wang, J. Sesquiterpenes and a monoterpenoid with acetylcholinesterase (AchE) inhibitory activity from Valeriana officinalis var. latiofolia in vitro and in vivo. Fitoterapia 2016, 110, 142. [CrossRef]

${ }^{81}$ Islam, M. M.; Rohman, M. A.; Gurung, A. B.; Bhattacharjee, A.; Aguan, K.; Mitra, S. Correlation of cholinergic drug induced quenching of acetylcholinesterase bound thioflavin-T fluorescence with their inhibition activity. Spectrochimica Acta Part A: Molecular and Biomolecular Spectroscopy 2018, 189, 250. [CrossRef] 